\title{
KARAKTERISTIK SIFAT FISIK TANAH GAMBUT OGAN KOMERING ILIR
}

\author{
Siti Muslikah ${ }^{1 *}$ dan Ida Yuliana ${ }^{1)}$ \\ 1) Jurusan Teknik Sipil, Fakultas Teknik, Universitas Islam Ogan Komering Ilir, Kayuagung
}

\begin{abstract}
Some areas of South Sumatra Province are peatlands scattered in the eastern part, starting from the districts of Musi Rawas, Musi Banyuasin, Ogan Komering Ilir, Muaraenim, and Banyuasin. Around 769,000 hectares of peatland are located in the Ogan Komering Ilir Regency area. Ogan Komering Ilir Regency is an area prone to forest fires. Therefore, it is necessary to conduct research on the characteristics of peat soils in the Ogan Komering Ilir area so that they can be used as consideration in efforts to prevent peatland fires. Sampling was carried out in Kotarayo Village, (Kayuagung District), SP 1 (Pedamaran Timur District), and Tulung Selapan Ilir Village (Tulung Selapan District). Peat soil samples were taken with ASTM D 7015-04 guidelines, and the physical properties of peat soil were tested for samples from the three locations. Based on its physical properties, peat soil samples are classified according to ASTM D4427-84. From the results of the research on peat soils in Kayuagung, Tulung Selapan, and Pedamaran Timur sub-districts, Ogan Komering Ilir Regency, peat soil samples can be classified as sapric-peat soil.
\end{abstract}

Key Words: classification, Kayuagung, peat soil, physical properties

\section{PENDAhuluan}

Total lahan gambut di dunia adalah 420 juta Ha, dimana sekitar 30-45 juta Ha merupakan tanah gambut dengan jenis tropika. Gambut Indonesia termasuk gambut tropika yang luasnya mencapai 14,9 juta Ha, tersebar di pulau Sumatera, Papua, dan Kalimantan. Luas gambut di pulau Sumatera sebesar $43,18 \%$ atau $6.436 .649 \mathrm{Ha}$, luas gambut di pulau Kalimantan sebesar 32,06\% atau seluas 4.778 .004 Ha, dan di Papua sebesar 24,76\% atau seluas 3.690.921 Ha. (Nurhayati dkk., 2020).

Sekitar 6.66 juta hektar $(44.6 \%)$ dari luas total lahan gambut di Indonesia, terdegradasi karena dimanfaatkan untuk berbagai kepentingan seperti pertanian, kehutanan, perkebunan dan pembangunan pemukiman. Deforestasi dan degradasi akibat aktivitas manusia dalam dua dekade terakhir berdampak pada peningkatan emisi karbon. Salah satu penyebab terjadinya degradasi lahan gambut adalah kebakaran hutan dan lahan gambut. Kebakaran pada lahan gambut sangat berbahaya karena sulit dideteksi dan dikendalikan.

Kebakaran gambut tidak dipengaruhi angin, sehingga pola penjalarannya tidak menentu serta sukar untuk menentukan dimana kebakaran sesungguhnya terjadi. Provinsi Sumatera Selatan memiliki sebaran areal kebakaran hutan dan lahan tertinggi dibandingkan provinsi lainnya pada tahun 2015. Sebagian kebakaran hutan dan lahan tersebut terjadi di Kabupaten Ogan Komering Ilir (OKI), sebesar 377.333 ha, dan sekitar 16 ribu hotspot (satellite-based thermal anomalies/fire locations) terdeteksi di Kabupaten OKI pada periode kebakaran tersebut (Nurlia dkk., 2018).

Kebakaran hutan dan lahan gambut menyebabkan terdegradasinya kondisi lingkungan seperti hilangnya sumber daya gambut dan hilangnya fungsi penyerapan karbon, serta berdampak pula pada aspek sosial ekonomi bagi masyarakat. Tidak hanya kerugian secara ekonomi, tetapi juga memengaruhi kesehatan manusia (Watts dan Kobziar, 2012).

Sebagian wilayah Provinsi Sumatera Selatan merupakan lahan gambut yang tersebar di daerah bagian timur, di Kabupaten: Musi Rawas, Musi Banyuasin, Ogan Komering Ilir, Muaraenim, dan Banyuasin. Sekitar 769.000 hektar lahan gambut terdapat di wilayah Kabupaten Ogan Komering Ilir (Wahyunto dkk., 2005).

Wilayah Kabupaten Ogan Komering Ilir terletak di bagian timur Provinsi Sumatera, yang memiliki bentang alam $25 \%$ daratan dan $75 \%$ rawa. Berdasarkan topografi, Kabupaten Ogan Komering Ilir merupakan dataran dengan ketinggian rata-rata 10 mdpl. Tipologi ekologi rawa meliputi sebagian besar wilayah Kabupaten Ogan Komering Ilir, meskipun secara lokal dapat ditemukan dataran kering. Wilayah Kabupaten Ogan Komering Ilir dibedakan menjadi dataran lahan basah dengan topografi rendah (lowland) dan dataran lahan kering yang memperlihatkan topografi lebih tinggi (upland). Daerah lahan basah hampir meliputi $75 \%$ wilayah 
Kabupaten Ogan Komering Ilir (Bappeda Kabupaten Ogan Komering Ilir, 2020).

Luas tanah gambut yang besar di wilayah kabupaten Ogan Komering Ilir, akan berpengaruh pada perencanaan pembangunan di wilayah tersebut, baik pembangunan infrastruktur, pertanian, perikanan, dan sosial ekonomi. Karena itu diperlukan studi tentang karanteristik tanah gambut di wilayah Ogan Komering Ilir, yang dapat dimanfaatkan sebagai bahan pertimbangan dalam upaya pencegahan kebakaran lahan gambut. Sebagai data tambahan yang dapat dijadikan pertimbangan dalam perencanaan pembangunan di Kabupaten Ogan Komering Ilir, hasil penelitian ini dapat dijadikan bahan untuk memahami karakteristik tanah gambut di Kabupaten Ogan Komering Ilir.

Menurut Hardiyatmo (2002), tanah gambut mengandung bahan organik yang tinggi, mudah mampat, memiliki kekuatan geser yang rendah, memiliki sifat asam yang dapat merusak material bangunan. Secara visual, tanah gambut dikenal sebagai massa berserat yang mengandung kekayuan, biasanya berwarna gelap dan berbau tumbuhan yang membusuk. PP No. 57 Tahun 2016 menyatakan bahwa gambut adalah material organik yang terbentuk secara alami dari sisa-sisa tumbuhan yang terdekomposisi.

Tanah organik memiliki berat isi kering yang sangat rendah, yaitu $0,2-0,3 \mathrm{kN} / \mathrm{m}^{3}$, dibandingkan dengan tanah mineral yang mempunyai berat isi kering mencapai $1,25-1,45 \mathrm{kN} / \mathrm{m}^{3}$. Hal ini dikarenakan, (dalam keadaan kering) tanah gambut sangat kering karena tanah organik mengalami dekomposisi lanjut.

Salah satu sifat tanah gambut adalah kemampuan menahan air yang sangat tinggi. Tanah gambut dapat menahan air sebesar 2-4 kali bobot airnya sedangkan tanah mineral hanya $1 / 2$ s.d $1 / 5$ kali dari bobotnya. Pada tanah gambut yang belum terdekomposisi, kemampuan menahan air dapat mencapai 12 s.d 20 kali bobot keringnya.

Menurut Hobbs (1986), karakteristik tanah gambut dapat ditentukan oleh beberapa hal, yaitu:

a) Warna.

Warna tanah gambut di lapangan dapat dijadikan petunjuk yang berguna. Tetapi warna tanah gambut cepat berubah jika terkena udara yang diduga merupakan hasil proses oksidasi sehingga harus dicatat di lapangan atau langsung dari tabung contoh tanah tak terganggu.

b) Tingkat dekomposisi (humifikasi)

c) Tingkat kebasahan (kadar air)

Dapat diukur secara akurat di laboratorium, tetapi untuk keperluan praktis di lapangan dapat dikategorikan dry, wet, very wet dan extremely wet.

d) Unsur utama
Tanah gambut memepunyai unsur utama yaiti fiber, fine, coarse, amorphous granular, material, woody material dan sebagainya.

e) Tanah mineral, pengenalan di lapangan sangat sulit kecuali jika memang terlihat jelas

f) $\mathrm{Bau}$

Bila tercium manusia, dapat dikategorikan menjadi tidak terlalu bau, agak berbau, berbau keras. Bau dari $\mathrm{H}_{2} \mathrm{~S}$ dapat tercium secara vertical maupun horizontal. Sedangkan bau metan hanya dapat terdeteksi dengan menggunakan detektor.

g) Komposisi Kimia

Pada tanah gambut, dekomposisi bahan-bahan organik yang terakumulasi pada tubuh tanah akan meningkatkan keasaman, sehingga tanah gambut cenderung lebih asam dengan tanah mineral dengan kebasahan sama.

h) Kekuatan tarik

i) Batas plastis yang dapat diuji atau tidak, merupakan petunjuk lapangan yang berguna dalam morfologi tanah gambut

Berdasarkan aspek teknis dan fisik tanah gambut, yaitu berdasarkan kandungan bahan organik, derajat dekomposisi dan jenis tanaman pembentuk serat, dapat dilakukan pengelompokkan tanah gambut. Mac Farlene \& Rodfort (1985) mengelompokkan tanah gambut berdasarkan kandungan seratnya, (Tabel 1). Sedangkan ASTM D4427-84 (1989) mengklasifikasikan tanah gambut berdasarkan kadar serat, tingkat keasaman, dan tingkat penyerapan/absorbs (Tabel 2 s.d Tabel 5).

Tabel 1. Klasifikasi Tanah Gambut berdasarkan Kandungan Serat Menurut Mac Farlene \& Rodfort (1985)

\begin{tabular}{cc}
\hline Jenis & Kadar Serat \\
\hline Fibrous peat & kandungan serat tanah gambut 20\% atau \\
(tanah gambut & lebih. Tanah gambut jenis ini memiliki \\
berserat) & dua jenis pori : makro pori dan mikro pori \\
Amorphous & kandungan serat tanah gambut kurang \\
granular soil, & dari $20 \%$. tanah jenis ini umumnya \\
& terdiri dari butiran berukuran koloid $(2 \mu)$ \\
& dan sebagian besar air porinya terserap di \\
& sekeliling permukaan butiran gambut \\
\hline
\end{tabular}

Tabel 2. Klasifikasi Tanah Gambut berdasarkan Kadar Serat Menurut ASTM D4427-84 (1989)

\begin{tabular}{cc}
\hline Jenis & Kadar Serat \\
\hline Fibric peat & $>67 \%$ \\
Helmic peat & $33-67 \%$ \\
Sapric peat & $<33 \%$ \\
\hline
\end{tabular}

Tabel 3. Klasifikasi Tanah Gambut berdasarkan Kadar Abu Menurut ASTM D4427-84 (1989)

\begin{tabular}{cc}
\hline Jenis & Kadar Serat \\
\hline Low ash peat & $<5 \%$ \\
Medium ash peat & $5 \%-15 \%$ \\
High ash peat & $>15 \%$ \\
\hline
\end{tabular}


Cantilever $\mid$ Volume: 10 Nomor: $02 \mid$ Oktober 2021 ISSN: 1907-4247 (Print) $\mid$ ISSN: 2477-4863 (Online) | Website: http://cantilever.id Siti Muslikah \& Ida Yuliana | Karakteristik Sifat Fisik Tanah Gambut Ogan Komering Ilir

Tabel 4. Klasifikasi Tanah Gambut berdasarkan Tingkat Keasaman Menurut ASTM D4427-84 (1989)

\begin{tabular}{cc}
\hline Jenis & Kadar Serat \\
\hline Highly Acidic & $<4.5$ \\
Moderarately Acidic & $4.5-5.5$ \\
Slightly Acidic & $>5.5-<7$ \\
Basic & $\geq 7$ \\
\hline
\end{tabular}

Tabel 5. Klasifikasi Tanah Gambut berdasarkan Kapasitas Menyimpan Air Menurut ASTM D4427-84 (1989)

\begin{tabular}{cc}
\hline Jenis & Kadar Serat \\
\hline ekstrim & $>1500 \%$ \\
tinggi & $800 \%-1500 \%$ \\
moderat & $300 \%-800 \%$ \\
kecil & $<300 \%$ \\
\hline
\end{tabular}

Penelitian tentang karakteristik sifat fisik tanah gambut wilayah Ogan Komering Ilir telah dilakukan sebelumnya pada wilayah Desa Pedamaran 1-Desa Jungkal, wilayah Desa Tanjung Serang-Desa Talang Seridang Tujuh, Penyabungan-Lebung Hitam, dan wilayah Air Sugihan-Lebung Gajah.

Berdasarkan laporan South Sumatera Forest Fire Management Project (2015), karakteristik tanah gambut pada wilayah Desa Pedamaran I-Desa Jungkal, Kecamatan Pedamaran memiliki kematangan gambut mentah (fibrik) pada kedalaman $1 \mathrm{~m}$. Sedangkan pada kedalaman $>1 \mathrm{~m}$ memiliki tingkat kematangan fibrik sampai hemik. Hal ini disebabkan gambut pada wilayah tersebut sering tergenang air, sehingga proses dekomposisi berjalan lambat karena kondisi aerob.

Karakteristik tanah gambut Desa Tanjung Serang-Desa Talang Seridang Tujuh, merupakan areal cekungan yang diperkirakan terbentuk oleh akumulasi luapan Sungai Lebak Sekitap dan Sungai Lebak Kecil serta sungai kecil disekitarnya. Kedalaman gambut yang terbentuk adalah bervariasi akibat permukaan tanah yang tidak sama. Sebagai hasil proses erosi dan edimetasi serta proses pelipatan yang terjadi pada masa orogenesis akhir (PlioPleistosen). Berdasarkan tingkat kematangan gambut, secara umum pada kedalaman $1 \mathrm{~m}$, rata-rata kematangan gambut setengah matang (hemik), Sedangkan pada kedalaman lebih dari 1 meter tingkat kematangan gambut sangat bervariasi dari Fibrik, Hemik sampai Safrik.

Karakteristik tanah gambut daerah PenyabunganLebung Hitam, Kecamatan Tulung Selapan memiliki tingkat keasamaan 3,18 s.d 4,70. Berdasarkan tingkat kematangan merupakan gambut dengan tingkat kematangan sedang (hemik), yang menunjukkan proses dekomposisi bahan organik belum maksimal. Tingginya kadar air di daerah ini memperlambat proses dekomposisi.

Dari hasil pengamatan lapangan, kualitas gambut di wilayah studi termasuk ke dalam jenis gambut ombragenus. Gambut ombragenus terbentuk di daerah pedalaman dataran pantai atau di daerah pasang surut, sehingga gambut ini relatif subur. Gambut ombragenus, memiliki ciri adanya tumpukan bahan organik yang membentuk kubah gambut (peat dome) dan memiliki ketebalan lebih 2 meter.

Karakteristik tanah gambut wilayah Air SugihanLebung Gajah Hasil mempunyai nilai keasaman antara $\mathrm{pH}$ 3,58 s.d 5,30, dan memiliki kematangan gambut berkisar antara fibrik, hemik, dan saprik. Kematangan gambut merupakan gambaran atas proses fisika kimia dan biologi tanah berkaitan dengan perubahan bentuk basah yang mentah menjadi lebih kering dan matang. Penentuan tingkat kematangan di lapangan dilakukan dengan uji peras (squeezing test), dimana tingkat kematangan gambut ditentukan berdasarkan penampakan hasil perasan.

Proses pembentukan gambut bahan organik yang masih kasar akan terus mengalami dekomposisi sehingga menjadi lebih halus. Dekomposisi bahan organik di pengaruhi oleh beberapa faktor, yaitu: susunan bahan organik, kelembaban, aktivitas mikroorganisme, kemasaman tanah, dan waktu.

Kabupaten Ogan Komering Ilir termasuk wilayah yang rawan kebakaran hutan. Terdapat dua faktor penyebab terjadinya kebakan tersebut, yaitu pemicu kebakaran dan kondisi pendukung. Faktor pemicu kebakaran terbesar disebabkan oleh aktivitas manusia. Sedangkan pemicu penyulutan api secara alami berasal dari batubara yang terbakar, halilitar, ataupun gesekan ranting kering. Namun, pemicu penyulutan api secara alami sangat jarang terjadi. Karena itu, perlu dilakukan penelitian tentang karanteristik tanah gambut yang ada di wilayah Ogan Komering Ilir agar dapat dimanfaatkan sebagai bahan pertimbangan dalam upaya pencegahan kebakaran lahan gambut.

Berdasarkan penjelasan di atas, rumusan masalah dalam penelitian ini adalah bagaimana mengidentifikasi sifat fisis tanah gambut di Kabupaten Ogan Komering Ilir, dengan sampel dari tiga lokasi kecamatan dalam wilayah Kabupaten Ogan Komering Ilir. Adapun uji sifat fisik yang dilakukan, meliputi:

1. Pengujian Kadar Air (Moisture Content)

2. Pengujian Berat volume

3. Pengujian Berat Jenis (Specific Gravity)

4. Pengujian Keasaman (pH)

5. Pengujian Kadar Organik ( Organic Content)

6. Pengujian Kadar Abu (Ash Content)

7. Pengujian Kadar Serat (Fiber Content)

Tujuan penelitian adalah mengetahui karakteristik tanah gambut di wilayah Kabupaten Ogan Komering Ilir berdasarkan sifat fisis tersebut. Sedangkan ruang lingkup dalam penelitian ini adalah: 
1. Menggunakan sampel tanah tidak terganggu (undisturbed sample) yang diambil di tiga lokasi, yaitu di Kecamatan Kayuagung, Kecamatan Tulung Selapan, dan Kecamatan Pedamaran Timur.

2. Pengujian dilakukan untuk mengetahui sifat fisis tanah gambut, yaitu: kadar air, berat jenis, tingkat keasaman, kadar serat, kadar abu, dan kadar organik tanah gambut.

\section{METODOLOGI}

Penelitian dilakukan dengan metode eksperimen untuk memperoleh data sifat fisis tanah gambut yang dapat digunakan untuk mengidentifikasi tanah gambut Kabupaten Ogan Komering Ilir. Pengambilan sampel tanah dilakukan di tiga wilayah kecamatan, yaitu: Kecamatan Kayuagung, Kecamtan Pedamaran Timur, dan Kecamatan Tulung Selapan.

Lokasi penelitian Sampel 1 berada di Kelurahan Kotarayo Kecamatan Kayuagung (koordinat 3024'49,692'S; 104051'4,764'T). Lokasi penelitian Sampel 2 di SP 1, Kecamatan Pedamaran Timur. (koordinat $\quad 3^{0} 33^{\prime} 10,878^{\prime \prime} \mathrm{S} ; \quad 105^{0} 2^{\prime} 30,546^{\prime}$ 'T). Sedangkan lokasi penelitian Sampel 3 di Desa Tulung Selapan Ilir, Kecamatan Tulung Selapan ( $\left.3^{\circ} 15^{\prime} 6,22 " \mathrm{~S} ; 105^{\circ} 17^{\prime} 54,73^{\prime \prime} \mathrm{T}\right)$.

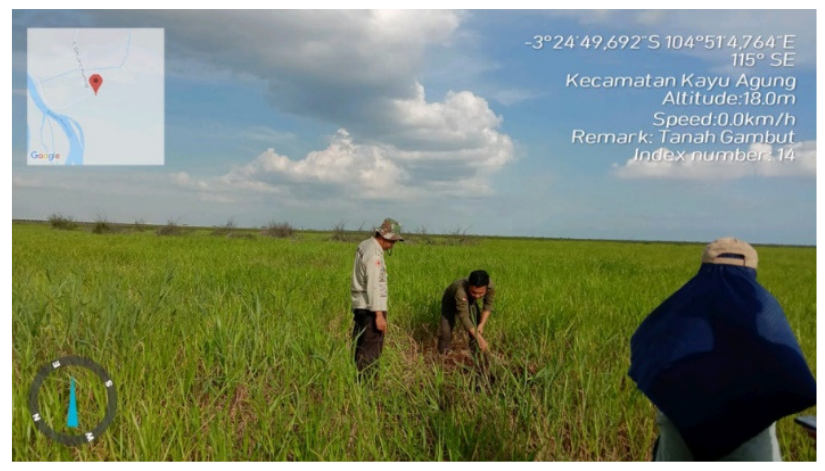

Gambar 1. Lokasi penelitian Sampel 1

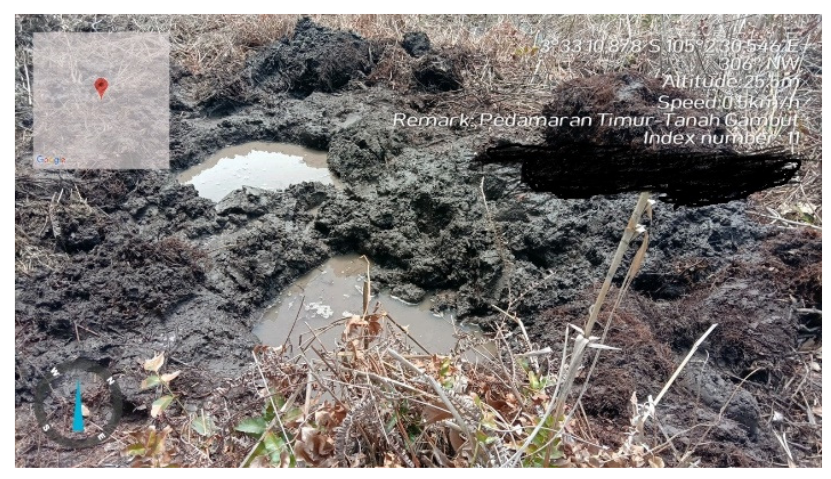

Gambar 2. Lokasi penelitian Sampel 2

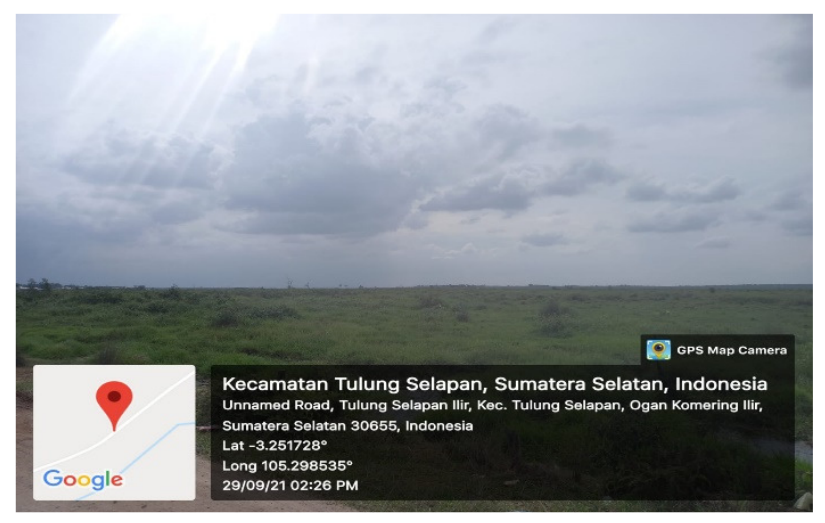

Gambar 3. Lokasi penelitian Sampel 3

Pengambilan sampel tanah gambut di lapangan mengacu pada ASTM D 7015-04, dengan prosedur sebagai berikut:

1. Gali tanah dengan kedalaman di bawah permukaan air tanah mengguunakan cangkul. Bersihkan dasar tanah dan buang ranting-ranting dan akar-akar sehingga tanah yang digunakan untuk sampel pengujian dalam kondisi yang baik dan sesuai yang dibutuhkan untuk pengujian

2. Dorong tabung yang berdiameter $15 \mathrm{~cm}$ dan tinggi $15 \mathrm{~cm}$ ke dalam tanah dengan hati-hati untuk mendapatkan sampel. Ketajaman tabung harus dipastikan untuk memotong serat yang menghalangi tabung dan untuk mengontrol kualitas sampel. Pisau yang tajam yang digunakan untuk membantu memotong serat di luar tabung jika diperlukan.

3. Gali sekitar tabung kemudian potong dasar tabung sampel dengan plat persegi $(20 \times 20 \mathrm{~cm})$ secara perlahan sehingga tanah tersebut tidak terganggu sesuai yang dibutuhkan dalam pengujian.

4. Masukkan sepotong plat kayu silinder dibawah sampel dan jaga sampel yang masih dalam tabung dengan menutup bagian atas dan bawah tabung, menggunakan kayu berdiameter sama dengan bagian dalam tabung.

5. Keluarkan tabung dengan hati-hati dan letakkan di tempat yang aman. Tutup bagian atas dan bawah tabung dengan lilin untuk menjaga kadar air.

6. Tutup lagi bagian atas dan bawah dengan menggunakan plat kayu persegi $(20 \times 20 \mathrm{~cm})$, dan ikat dengan tali agar tabung aman selama dalam perjalanan.

Selanjutnya, dilakukan uji sifat fisis tanah gambut di Laboratorium Mekanika Tanah Universitas Sriwijaya. Pengujian laboratorium dimulai dari pekerjaan persiapan, yaitu: penyediaan sampel tanah, alat-alat, serta bahan-bahan yang diperlukan dalam pengujian. 
Cantilever | Volume: 10 Nomor: 02 | Oktober 2021 ISSN: 1907-4247 (Print) | ISSN: 2477-4863 (Online) | Website: http://cantilever.id Siti Muslikah \& Ida Yuliana | Karakteristik Sifat Fisik Tanah Gambut Ogan Komering Ilir

\section{HASIL DAN PEMBAHASAN}

Hasil analisis laboratorium terhadap sampel tanah gambut Kabupaten Ogan Komering Ilir untuk sampel Kecamatan Kayuagung, Kecamatan Tulung Selapan, dan Kecamatan Pedamaran Timur ditunjukkan dalam Tabel 6.

Tabel 6. Hasil Analisis Sifat Fisik Tanah Gambut.

\begin{tabular}{|c|c|c|c|}
\hline Parameter & Kayuagung & $\begin{array}{l}\text { Tulung } \\
\text { Selapan }\end{array}$ & $\begin{array}{l}\text { Pedamaran } \\
\text { Timur }\end{array}$ \\
\hline Kadar air (\%) & 820,13 & 721,56 & 720,26 \\
\hline $\begin{array}{l}\text { Kadar organik, } \\
(\mathrm{g} / \mathrm{kg})\end{array}$ & 76,82 & 84,26 & 85,04 \\
\hline Berat jenis $\mathrm{G}_{\mathrm{s}}$ & 1,35 & 1,71 & 1,67 \\
\hline $\begin{array}{l}\text { Kadar serat, FC } \\
(\%)\end{array}$ & 23,52 & 13,83 & 17,64 \\
\hline $\begin{array}{l}\text { Kadar abu, AC } \\
(\%)\end{array}$ & 23,12 & 15,74 & 14,96 \\
\hline Agka pori (e) & 4,52 & 2,41 & 3,43 \\
\hline $\mathrm{pH}$ & 4,18 & 3,23 & 4,98 \\
\hline
\end{tabular}

Berdasarkan hasil analisis sifat fisik, sampel tanah gambut Kayu Agung termasuk jenis tanah gambut matang dan berserat, memiliki tinggi keasaman dan kadar abu yang tinggi, dan kemampuan menyerap air yang tinggi. Sampel tanah gambut Tulung Selapan termasuk tanah gambut matang, memiliki kandungan serat yang sedikit, memiliki tingkat keasaman dan kadar abu yang tinggi, dengan kemampuan menyerap air sedang. Sedangkan sampel tanah gambut di Pedamaran Timur termasuk jenis tanah gambut matang yang sedikit berserat, memiliki kadar abu dan tingkat keasaman sedang, dan memiliki kemampuan menyerap air sedang. Perbandingan klasifikasi tanah gambut untuk tiga sampel tanah dari tiga kecamatan di Kabuaten Ogan Komering Ilir dapat dilihat pada Tabel 7.

Tabel 7. Klasifikasi Sampel Tanah Gambut Kecamatan Kayuagung, Tulung Selapan, dan Pedamaran Ttimur, Kabupaten Ogan Komering Ilir

\begin{tabular}{|c|c|c|c|}
\hline \multirow{2}{*}{$\begin{array}{c}\text { Klasifikasi } \\
\text { Tanah } \\
\text { Gambut }\end{array}$} & \multicolumn{3}{|c|}{ Kecamatan } \\
\hline & Kayuagung & $\begin{array}{l}\text { Tulung } \\
\text { Selapan }\end{array}$ & $\begin{array}{c}\text { Pedamaran } \\
\text { Timur }\end{array}$ \\
\hline $\begin{array}{l}\text { Berdasarkan } \\
\text { kadar serat (Mac } \\
\text { Farlee \& } \\
\text { Rodfort, 1965) }\end{array}$ & $\begin{array}{l}\text { Fibrous peat } \\
\text { (tanah gambut } \\
\text { berserat) }\end{array}$ & $\begin{array}{l}\text { Amorphous } \\
\text { granular soil }\end{array}$ & $\begin{array}{l}\text { Amorphous } \\
\text { granular soil }\end{array}$ \\
\hline Berdasarkan & sapric-peat & sapric-peat & sapric-peat \\
\hline kadar serat & $\begin{array}{l}\text { soil (gambut } \\
\text { matang) }\end{array}$ & $\begin{array}{l}\text { soil (gambut } \\
\text { matang) }\end{array}$ & $\begin{array}{l}\text { soil (gambut } \\
\text { matang) }\end{array}$ \\
\hline Kadar Abu & $\begin{array}{l}\text { kadar abu } \\
\text { tinggi (high } \\
\text { ash peat) }\end{array}$ & $\begin{array}{l}\text { kadar abu } \\
\text { tinggi (high } \\
\text { ash peat) }\end{array}$ & $\begin{array}{l}\text { kadar abu } \\
\text { sedang } \\
\text { (medium ash } \\
\text { peat) }\end{array}$ \\
\hline $\begin{array}{l}\text { Tingkat } \\
\text { keasaman }(\mathrm{pH})\end{array}$ & Highly acidic & Highly acidic & $\begin{array}{l}\text { Moderarately } \\
\text { acidic }\end{array}$ \\
\hline $\begin{array}{l}\text { Berdasarkan } \\
\text { daya serap }\end{array}$ & tinggi & moderat & moderat \\
\hline
\end{tabular}

Berdasarkan Tabel 7, klasifikasi sampel tanah Gambut di Kecamatan Kayuagung, Tulung Selapan, dan Pedamaran timur, Kabupaten Ogan Komering Ilir memiliki satu kesamaan klasifikasi berdasarkan kadar seratnya, yaitu diklasifikasikan sebagai tanah gambut matang (sapric-peat soil).

\section{KESIMPULAN}

Berdasarkan hasil penelitian, sampel tanah gambut di Kecamatan Kayuagung, Tulung Selapan, dan Pedamaran Timur, Kabupaten Ogan Komering Ilir memiliki kesamaan dalam hal kandungan kadar serat, yaitu termasuk tanah gambut matang (sapricpeat soil). Sampel tanah gambut Kayuagung termasuk jenis tanah gambut matang, dan berserat, memiliki tinggi keasaman dan kadar abu yang tinggi, dan kemampuan menyerap air yang tinggi. Sampel tanah gambut Tulung Selapan termasuk tanah gambut matang dan memiliki kandungan serat yang sedikit, memiliki tingkat keasaman dan kadar abu yang tinggi, dengan kemampuan menyerap air sedang. Sedangkan sampel tanah gambut Pedamaran Timur termasuk jenis tamah gambut matang yang sedikit berserat, memiliki kadar abu dan tingkat keasaman sedang, dan memiliki kemampuan menyerap air sedang.

\section{REFERENSI}

ASTM D 4427-84. Standard Classification of Peat Samples by Laboratory Testing.

ASTM D 7015-04. Standard Practices for Obtaining Undisturbed Block (Cubical and Cylindrical) Samples of Soils

Bappeda Kabupaten Ogan Komering Ilir (2020). Profil Perumahan dan Kawasan Pemukiman Kabupaten Ogan Komering Ilir. Kayu Agung, OKI: Bappeda OKI

Hardiyatmo, H. C. (2002). Analisis dan Perancangan Teknik Pondasi I. Yogyakarta: Beta Offset.

Hobbs, N.B. (1986). Mire Morphology and The Properties and Behaviour of Some British and Foreign Peats, Quart. J. of Eng. Geol., 19, 7-80.

MacFarlane, I. C. and Radforth, N. W. (1965). A Study of the Physical Behavior of Peat Derivatives Under Compression, Proc. Of the Tenth Muskeg Research Conference, National Research Council of Canada, Technical Memorandum No. 85.

Nurhayati A. D., Saharjo B.H., Sundawati L, Sundawati L., Syartinilia, Vetrita Y. (2020). Perilaku dan persepsi masyarakat terhadap terjadinya kebakaran gambut di Kabupaten Ogan Komering Ilir Provinsi Sumatera Selatan. JPSL 10(4), 568-583.

Nurlia A., Waluyo E.A., \& Martin E. (2018). Efektivitas Kebijakan Pembukaan Lahan Tanpa Bakar Dalam Mengurangi Kejadian Kebakaran di Lahan Gambut (Kasus di Rengas Merah, Kabupaten OKI, Sumatera Selatan). Dalam: Hesti L.T., Lailan S., Mamat R., \& Edwin M. (editor). Merawat Asa Restorasi Gambut, Pencegahan Kebakaran dan Peningkatan Kesejahteraan Masyarakat Palembang: Prosiding (hal 105-113).

Peraturan Pemerintah (PP) No. 57 Tahun 2016 tentang Perubahan atas Peraturan Pemerintah Nomor 71 Tahun 
2014 tentang Perlindungan dan Pengelolaan Ekosistem Gambut.

South Sumatera Forest Fire Management Project, (2015). Coastal Peat Survey in District Ogan Komering Ilir Tulung Selapan Sub District. Palembang: Pusat Penelitian Manajemen Air Dan Lahan Lembaga Penelitian Universitas Sriwijaya.

South Sumatera Forest Fire Management Project. (2015). Kajian Karakteristik Gambut di Wilayah Hutan Kayu Agung (Pedamaran dan Pampangan) Kabupaten Ogan Komering Ilir (OKI). Palembang: Pusat Penelitian Manajemen Air Dan Lahan Lembaga Penelitian Universitas Sriwijaya.

Wahyunto, S. Ritung, Suparto, \& H. Subagjo. (2005). Peatland Distribution and Its Content in Sumatra and Kalimantan. Bogor: Wetland International - Indonesia Programme and Wildlife Habitat Canada.

Watts A.C. \& Kobziar L.N. (2012). Smoldering Combustion in organic Soils: Peat and Muck Fires in the Southeastern U.S. Diunduh tanggal 01 Mei 2020 pada: www.southernfireexhchange.org. 